\title{
The Optimization of Internal Processes from a Screw Compressor with Oil Injection to Increase Performances
}

\author{
Sorin Neacşu, Cristian Eparu*, Adrian Neacșa \\ Petroleum - Gas University of Ploiesti, 39 Bucharest Blvd., Ploiesti (100680), Romania
}

Corresponding Author Email: cristian.eparu@gmail.com

https://doi.org/10.18280/ijht.370118

Received: 15 September 2018

Accepted: 20 February 2019

\section{Keywords:}

energy, entropy, gas, irreversible, modelling, optimization, screw compressor

\begin{abstract}
The aim of this study is to assess how the compression equipment may work to the maximum performances with minimum consumptions. A functional dynamic model was designed so that the screw compressor process may be analyzed and a strategy for modelling and optimization of the compression equipment to be further established. The paper presents a method of functional optimization for the screw compressor in the direction of decreasing the necessary compression power using the injected oil flow. This process significantly modifies the thermodynamic parameters of the compression so that it allows using the phenomenon for the functional optimization. The results indicate that for each regime of functioning the optimum oil flow which can be injected may be found at the intersection of the two curves representing compressor power and irreversible lost power. The findings of this research lead to a significant reduction in the operating costs.
\end{abstract}

\section{INTRODUCTION}

The continuous evolution of demand and offer for the natural gas in Europe, but also in Romania, leads to the necessity of increasing the natural gas pressure at the 45 bar values in the Romanian National Gas Transport System. Considering the development strategy of Transgaz, but also the diminished gas pressure from sources, the INCDTCOMOTI responded to this tendency and made screw compressors at high pressure of repression by modifying the trademark compressors to obtain 45 bar at the maximum pressure of repression.

The screw compressor is a volumetric compressor (see Figure 1). The gas is compressed inside the machine by moving forward with the help of two screws. Taking into consideration the machine seal and function during the process, the oil is injected in the majority of those types of compressors.

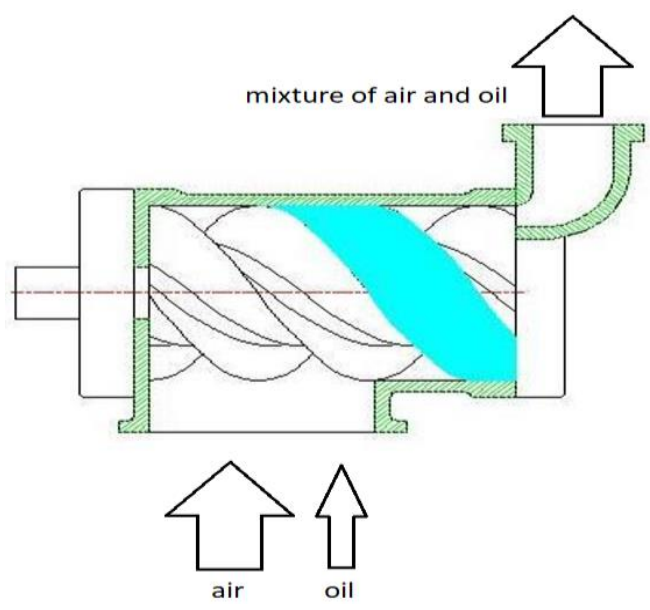

Figure 1. Volumetric compressor - screw compressor
The oil is recovered, cooled and will be returned in process. The oil injection modifies radically the thermodynamic process of compression in a positive way [1]. The determination of the optimal regime implies finding the values of functional parameters so that the equipment may work to the maximum performances with minimum consumptions. Generally, from a technical point of view, the oil injection is performed during the process of aspiration; this operation generates the wear minimization and the seal maximization of parts.

In Figure 2 there are represented the characteristics of the compression adiabatic process [2-4] overlain with those of a process in which the gas gives heat to the environment (oil). The oil injection enhances the heat exchange from compressor, the compressed gas gets hot during the process but the oil being colder takes only a part from that heat [5]. In Figure 2 there are represented two compression processes in comparison, one adiabatic and the other in which the gas gives heat to the oil.

From the analysis of the characteristics it can be observed that the heat exchange between the compressed gas and the oil makes that the real process of compression be very close to an isothermal process that is the ideal process because less energy is spent to obtain the same final pressure.

This paper establishes a model that analyzes this influence with the aim to optimize the compression process from a screw compressor with oil injection. The findings lead to a software development that integrates compression process optimization with reliability, maintenance and economics.

The remainder of this paper is organized as follows: Section 2 introduces the theoretical considerations used to design the functional dynamic model that analyze the screw compressor process, Section 3 presents and analyzes the results obtained for the influence of the oil flow rate on the thermodynamic process. 


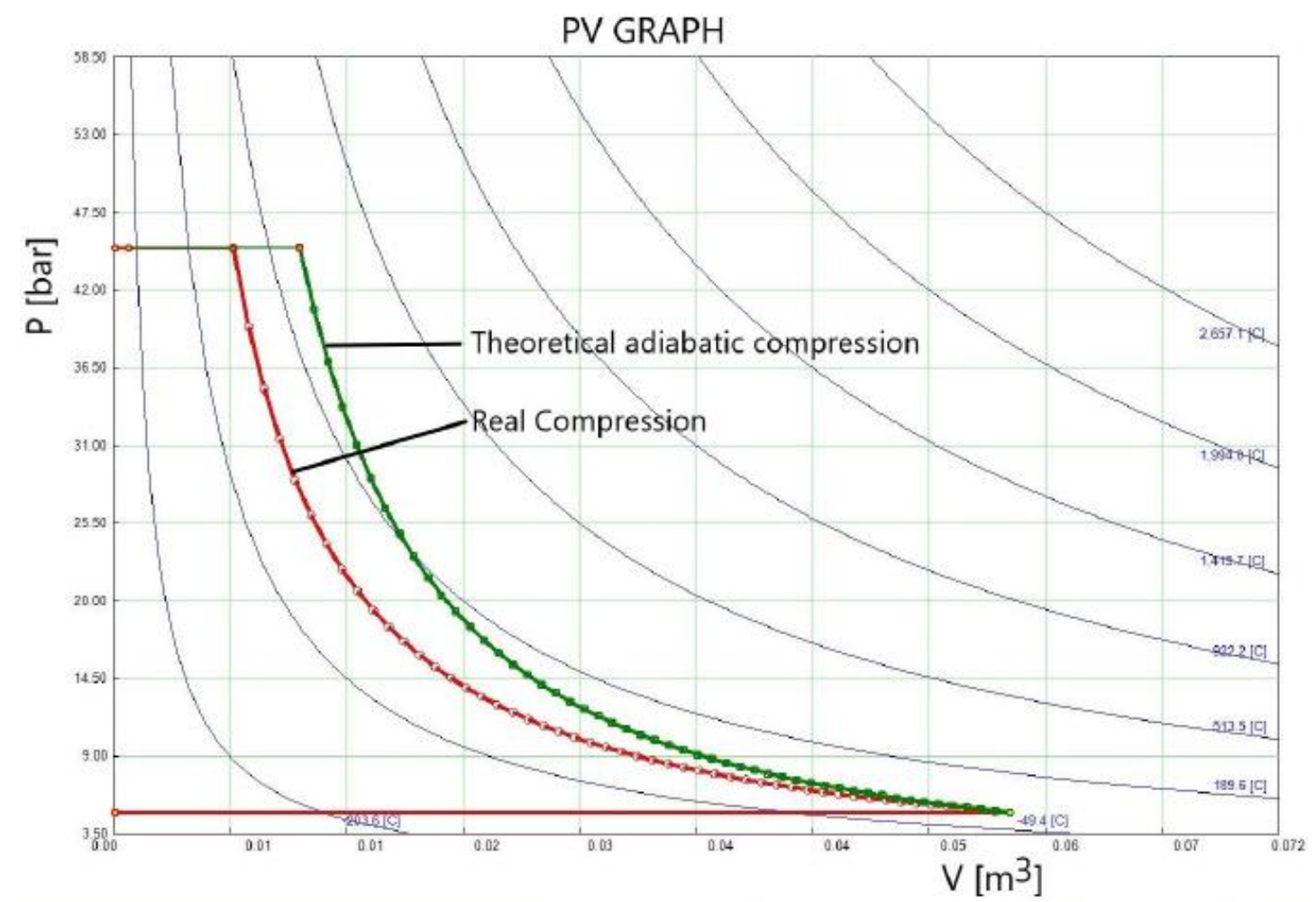

Figure 2. Comparison between an adiabatic compression and real process

\section{THEORETICAL CONSIDERATIONS}

A functional dynamic model was designed so that the screw compressor process may be analyzed. The main flows taken into consideration (see Figure 3) are:

$>$ Masic flows $\mathrm{m}_{\mathrm{a}}, \mathrm{m}_{\mathrm{o}}$ and $\mathrm{m}_{\mathrm{a}+\mathrm{o}}$ for air and oil;

$>$ Energy for air and oil $\mathrm{E}_{\mathrm{a}}, \mathrm{E}_{\mathrm{o}}$ and $\mathrm{E}_{\mathrm{a}+\mathrm{o}}$;

$>$ Necessary power for compressor $\mathrm{P}_{\mathrm{c}}$ and the lost power due to the irreversibility of thermodynamic processes;

$>$ Lost heat flow by the machine to the environment $\mathrm{Q}_{\mathrm{p}}$ and the correspondent entropy flow $\mathrm{S}_{\mathrm{Qp}}$;

$>$ The entropy flows that go through the machine for air and oil $S_{a}, S_{o}$ and $S_{a+o}$.

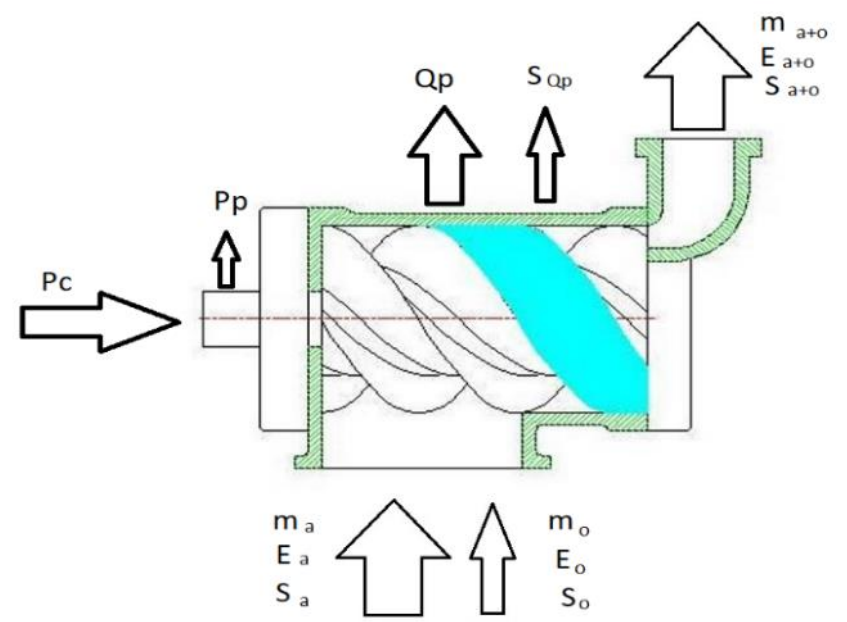

Figure 3. Functional dynamic model for a screw compressor

For the model presented in Figure 3 were used the following equations [6-8]:

1. Mass conservation law - Eq. (1): $\frac{d m}{d \tau}+\sum \dot{m}_{e}-\sum \dot{m}_{i}=0$

2. Energy conservation law - Eq. (2):

$\dot{Q}+\sum \dot{m}_{i}\left(h_{i}+\frac{w_{i}^{2}}{2}+g Z_{i}\right)=$

$=\sum \dot{m}_{e}\left(h_{e}+\frac{w_{e}^{2}}{2}+g Z_{e}\right)+\dot{L}_{t}$

3. Entropy balance for open systems - Eq. (3):

$\dot{S}_{g e n}=\frac{\partial S}{\partial \tau}-\frac{\dot{Q}}{T}+\sum \dot{m}_{i} s_{i}-\sum \dot{m}_{e} s_{e}$

4. Gouy-Stodola's theorem for lost power calculation - Eq. (4):

$P_{p}=T_{0}\left(\frac{\partial S}{\partial \tau}-\frac{\dot{Q}}{T_{0}}-\sum \dot{m}_{i} S_{i}+\sum \dot{m}_{e}\right)=T_{0} S_{g e n}$

Based on the relations from above, a screw compressor with oil injection was created. For the accuracy of the obtained values, the numerical result obtained from the created model were calibrated, for specific regimes, with experimental data so that at the work regime, the outer and inner parameters must be identical, see figure 4 . In this case, the calibration parameter was the outer temperature of oil and gas mixture and the model gave the value presented below in Figure 4.

Air and oil outlet temperature [grd $\mathrm{C}]=78.75$

Air outlet temperature for a theoretical adiabatic process [ grd. $C$ ] $=325.08$

Adiabatic exponent of real compression $=1.05850$

Entropy generation rate $[\mathrm{kJ} / \mathrm{K} / \mathrm{s}]=0.039$

Figure 4. Calibration parameter - result 


\section{RESULTS PRESENTATION}

The variable parameter that was taken into consideration for the process optimization was the oil flow of compressor cooling. Simulating many functional regimes with numerical model we obtained the results presented in Figure 5.

\subsection{The influence of the oil flow rate injected on the output temperature of compressed gases}

Being a very important parameter for the compressor functionality, in Figure 5 we presented the output temperature variation of the compressed gas versus the injected oil flow rate. Generally, the compressed gas temperature increases during the compression process but for the screw compressor with oil injection one can observe that the temperature decreases according to the oil injected flow rate, fact that can be explained by the part of heat of compressed gas that the oil takes.

The numerical laboratory experiments used air as the work environment. The inner temperature of the screw compressor by oil injection was of $30^{\circ} \mathrm{C}$. It can be observed that, once with oil flow increasing, the output temperature of the compressed air decreases, results that the thermodynamic process evolves from an adiabatic process to an isothermal one, fact that determines the significantly reduction of compression mechanical work.

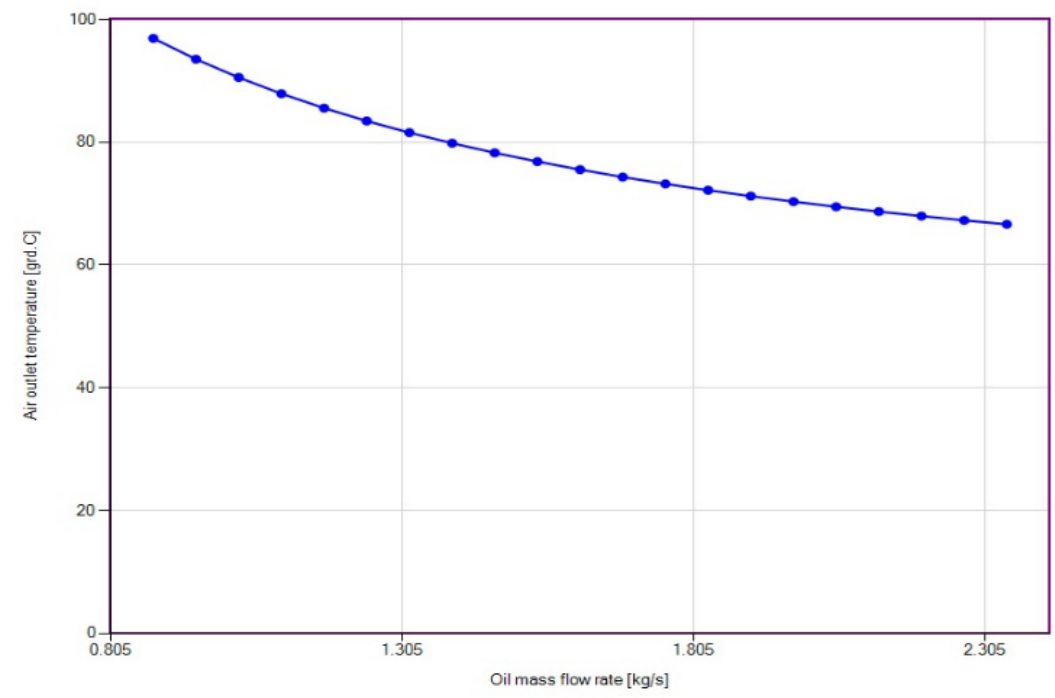

Figure 5. Gas exit temperature versus oil flow rate

3.2 The influence of oil flow rate on the compression adiabatic exponent and on the entropy generation rate

In figure 6 are represented the results referring to the real adiabatic exponent of the compression and the speed of entropy generation.

Based on the obtained data can be observed that due to the oil cooling the value of the adiabatic exponent is reduced (the value for air is 1.4) to values close to 1 so confirm that the real compression process is similar to an isothermal process fact that determines the maintaining of a low temperature regime of compressor during the functioning and also a reduced power necessary to machine entrainment.

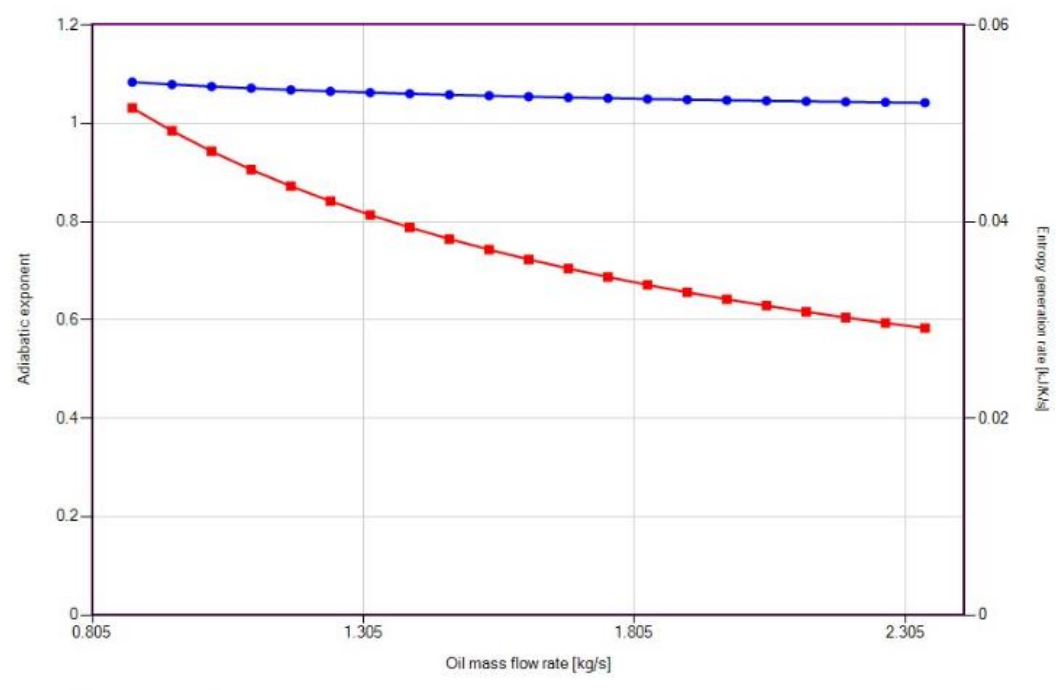

Figure 6. The real adiabatic exponent of the compression and the speed of entropy generation 
A bigger influence can be observed in the speed of entropy generation. The entropy is influenced by two elements:

a. The heat flow generated of friction that in this case stays almost constant;

b. The exchange heat between air and oil.

The cooling air is stronger than oil heating so that per assembly it will result a decrease in entropy generation speed which means the increase of economy process.

\subsection{The influence of the oil injection on the compression power and on the lost power due to the irreversibility of process}

In Figure 7 is represented the situation of the mechanical power necessary for the machine entrainment. It can be observed that the necessary power for the compressor entrainment increase according to the increase of the oil flow.

The more oil is injected the more compressed necessary power increases, fact that is explained through the power depend on the mass flow, the oil having big density, concur at the increasing of air \& oil specific mass flow.

This behavior represents a negative effect of the oil flow increase so that it is necessary to impose a limit of the flow when negative effects become more important than the positive ones.

The lost power due to the irreversibility of process decreases because from the thermodynamic point of view it can get closer to an ideal isothermal process.

In conclusion to the above paragraphs presented it results that the optimum oil flow which can be injected may be found at the intersection of the two curves.

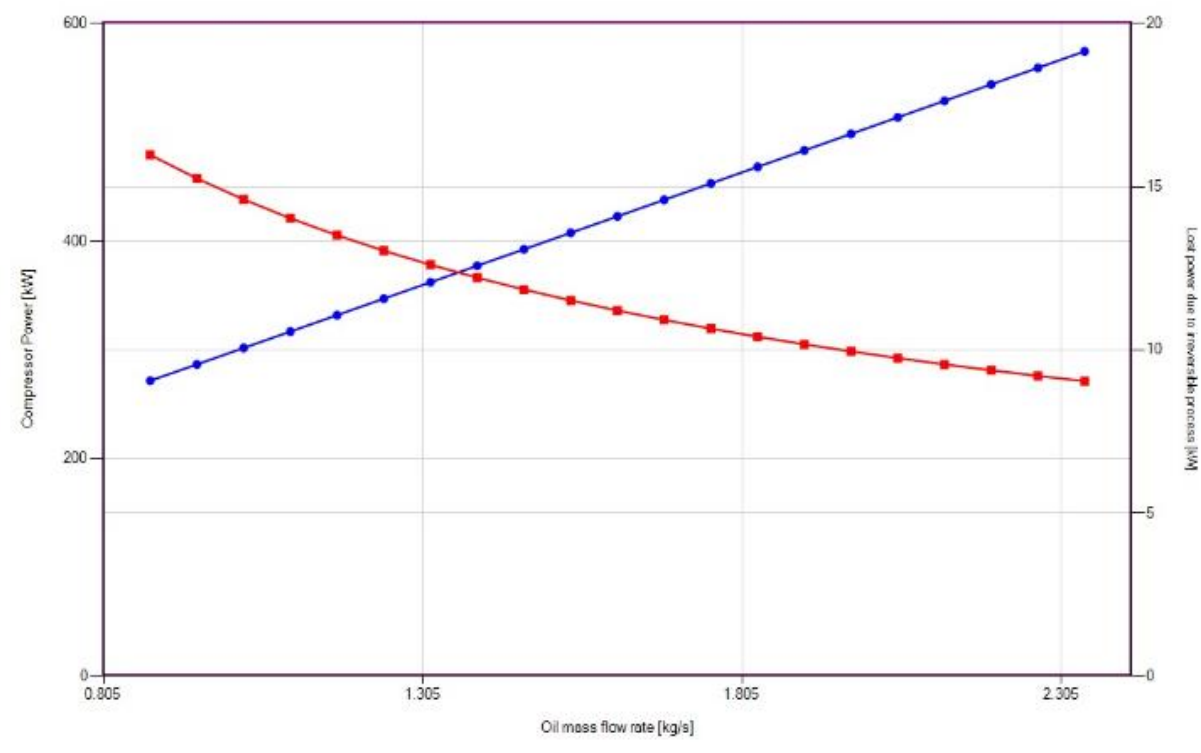

Figure 7. Required mechanical powers for the machine entrainment by dependent of the oil flow

\section{CONCLUSIONS}

In the conditions of the natural gas demand increasing, respectively the transportation pressure and reducing of the resources or their pressure it is necessary an increase in compression rates and/or a more efficient and reliable compressors.

The oil injection in screw compressors modifies in a positive way the compression process which means that it will be closer to an ideal isothermal process. The main effect which influences the compression is the heat exchange between oil and gas. The compressors are energy-consumer and a goal in the designing and the manufacturing of compressor is to reduce that energy consumption. Due to the specific process, the screw compressors can be designed so that the energy consumption is minimal for each process.

The oil injection used in technological processes for the minimization of frictions and to favor the two wounded wheel gear influences the thermodynamic process. The used oil flow may be varying between some limits which do not affect too much the compressor functioning.

It is obvious that increase of the oil flow has benefic effects if we refer to the improvement of thermodynamic process, but it also has negative influences because it implies the necessary power increase for compression. Because of this, it must be found an optimum oil flow for each regime of functioning which means the important economies resulting from the evolution of technological process but also in the reliability of the equipment parts.

The minimal energy consumptions for compressors is achieved by optimizing the compression process fact that means a significant reduction in the operating costs.

Integrating the compression process optimization with reliability, maintenance and economics in a software in order to achieve a complete optimization for the compressor is the next stage that one can foresee in further research.

\section{ACKNOWLEDGMENT}

This research was part of a project financed by Executive Unit for Financing Higher Education, Research, Development and Innovation (UEFISCDI) within Bridge Grant (Knowledge Transfer to the Enterprise). 


\section{REFERENCES}

[1] Ştefănescu M, Silivestru V, Liviu A, Neacşu S, Florea I, Eparu C. (2008). Mentenanța turbomotoarelor. Editura Universității Petrol-Gaze din Ploieşti, Ploieşti, Romania.

[2] Stosic N, Smith I, Kovacevic A. (2005). Screw compressors mathematical modeling and performance calculation. Springer Verlag Berlin Heidelberg.

[3] API 619. (2010). Rotary - Type positive-displacement compressors for petroleum, petrochemical and natural gas industries.

[4] ISO10440-1. (2007). Petroleum and natural gas industries/Rotary-type positive-displacement compressors. Part 1/ process gas compressors.

[5] Li S, Zhang YD, Li Y, Liao RQ. (2015). Equilibrium calculation and technological parameters optimization of natural gas liquefaction process with mixed refrigerant. International Journal of Heat and Technology 33(2): 123128. http://dx.doi.org/10.18280/ijht.330220

[6] Neacsu S. (2009). Comprimarea și lichefierea gazelor, Editura Romconvert, Ploiești, Romania.

[7] Neacșu S. (2009). Termotehnică și mașini termice, Editura Printeh, București, Romania.

[8] Van Wylen G, Sonntag R, Borgnakke C. (1994). Fundamentals of Classical Thermodynamics. Jon Wiley \& Sons New York, USA.

\section{NOMENCLATURE}

M

masic flow rate

$\begin{array}{ll}\mathrm{E} & \text { Energy } \\ \mathrm{P}_{\mathrm{c}} & \text { Compressor power } \\ P_{p} & \text { Lost Power } \\ \mathrm{Q}_{\mathrm{p}} & \text { Lost heat flow to the environment } \\ \mathrm{S}_{\mathrm{Qp}} & \text { Entropy lost to the environment } \\ \mathrm{S} & \text { Entropy } \\ \dot{m}_{e} & \text { Masic flow rate exiting the system } \\ \dot{m}_{a} & \text { Masic flow rate entering the system } \\ \dot{Q} & \text { Thermal power } \\ w & \text { Speed } \\ h & \text { Entalpy } \\ g & \text { gravitational acceleration, } \mathrm{m}_{\mathrm{s}} \mathrm{s}^{-2} \\ Z & \text { Elevation } \\ \dot{L}_{t} & \text { Mechanical Power } \\ \dot{S}_{g e n} & \text { generated Entropy } \\ T & \text { Temperature } \\ T_{0} & \text { environment temperature }\end{array}$

\section{Greek symbols}

$\tau$

time, s

\section{Subscripts}

$\begin{array}{ll}\mathrm{a} & \text { Air } \\ \mathrm{o} & \text { Oil } \\ \mathrm{a}+\mathrm{o} & \text { air and oil } \\ \mathrm{i} & \text { Input } \\ \mathrm{e} & \text { Exit }\end{array}$

